\title{
Antimicrobial resistance patterns and biofilm formation of coagulase-negative Staphylococcus species isolated from subclinical mastitis cow milk samples submitted to the Onderstepoort Milk Laboratory
}

\author{
Lufuno Phophi', Inge-Marie Petzer ${ }^{2}$ and Daniel Nenene Qekwana ${ }^{1 *}$ (D)
}

\begin{abstract}
Background: Increased prevalence of antimicrobial resistance, treatment failure, and financial losses have been reported in dairy cows with coagulase-negative Staphylococcus (CoNS) clinical mastitis, however, studies on CoNS infections are limited in South Africa. Therefore, the objectives of this study were to investigate the antimicrobial resistance patterns and biofilm formation in CoNS isolated from cow milk samples submitted to the Onderstepoort Milk Laboratory.

Results: A total of 142 confirmed CoNS isolates were used for this study. Biofilm formation was identified in 18\% of CoNS tested. Staphylococcus chromogenes (11\%) had the highest proportion of biofilm formation followed by S. haemolyticus (4.0\%), S. epidermidis, S. hominis, S. xylosus, and S. simulans with 1\% respectively. Ninety percent (90\%) of CoNS were resistant to at least one antimicrobial (AMR) and 51\% were multidrug-resistant (MDR). Resistance among CoNS was the highest to ampicillin (90\%) and penicillin (89\%), few isolates resistant to cefoxitin and vancomycin, 9\% respectively. Similarly, MDR-S. haemolyticus (44\%), MDR-S. epidermidis (65\%), and MDR-S. chromogenes (52\%) were mainly resistant to penicillins. The most common resistance patterns observed were resistance to penicillin-ampicillin (16\%) and penicillin-ampicillin-erythromycin (10\%). Only $42 \%$ of biofilm positive CoNS were MDR.

Conclusion: The majority of CoNS in this study were resistance to penicillins. In addition, most isolates were $\beta$ lactam resistant and MDR. Biofilm formation among the CoNS in this study was uncommon and there was no significant difference in the proportion of MDR-CoNS based on the ability to form a biofilm.
\end{abstract}

\section{Background}

Coagulase negative Staphylococcus (CoNS) are among the most frequently isolated bacteria from dairy cows with clinical and subclinical mastitis [1-3]. They are emerging as opportunistic pathogens in clinical mastitis in South Africa [4] and globally [5-10]. The most

\footnotetext{
* Correspondence: nenene.qekwana@up.ac.za

${ }^{1}$ Section Veterinary Public Health, Department of Paraclinical Sciences, Faculty of Veterinary Science, University of Pretoria, Private Bag X04, Onderstepoort 0110, South Africa

Full list of author information is available at the end of the article
}

commonly isolated CoNS in subclinical and clinical mastitis include S. chromogenes, S. epidermidis, S. simulans, S. haemolyticus, and S. xylosus [2, 11, 12]. Although intramammary infections caused by CoNS are usually self-limiting, however, there are reports of clinical mastitis cases that often require antimicrobial treatment [13, 14]. Penicillin antimicrobials have been reported to be effective against CoNS infections [9, 15, 16]. However, studies are reporting increasing prevalence of antimicrobial resistance in CoNS from clinical mastitis cases [17-

(c) The Author(s). 2019 Open Access This article is distributed under the terms of the Creative Commons Attribution 4.0 International License (http://creativecommons.org/licenses/by/4.0/), which permits unrestricted use, distribution, and 
19] including resistance to penicillin, tetracycline, lincomycin, and streptomycin [13, 20].

The increasing prevalence of resistance among CoNS could be due to the injudicious use of antimicrobials [21], the presence of penicillin binding protein $2 \mathrm{a}$ (PBP2a) $[16,22,23]$, and mecA mediated oxacillin resistance [2427]. In addition, the high prevalence of antimicrobial resistance among CoNS could be due to their ability to form a biofilm which facilitates persistent infections $[9,28$, 29 ] and decreases susceptibility to commonly used antimicrobials [30]. The ability of Staphylococcus species to form biofilm has been linked to the presence of biofilm-forming genes such as icaA and bap gene [20,30,31], which have been isolated in CoNS species such as S. epidermidis, $S$. haemolyticus, S. xylosus, S. chromogenes and S. simulans [31]. To our knowledge, there are no studies that have reported an association between biofilm formation and high prevalence of MDR in CoNS isolated from subclinical mastitis cases in dairy cattle. In addition, no studies have been published on the antimicrobial resistance patterns of CoNS from dairy cattle in South Africa.

Thus, the aim of this study was to investigate the antimicrobial resistance patterns and biofilm formation of CoNS isolated from cow milk samples submitted to the Onderstepoort milk laboratory, Department of Production Animal Studies, South Africa. We hypothesize that CoNS with biofilm formation isolated from subclinical mastitis cases have an increased prevalence of resistance to commonly used antimicrobials. In addition, it also possible that these isolates are $\beta$-lactam and multidrugresistant (MDR).

\section{Results}

\section{Coagulase negative Staphylococcus species}

A total of 142 CoNS isolates were tested for biofilm formation and antimicrobial resistance, the majority of the isolates tested were S. chromogenes (70\%; 100/142), followed by $S$. epidermidis (12\%; 17/142), S. haemolyticus (11\%; 16/
142), S. simulans (2\%; 3/142),S. xylosus (2\%; 3/142), S. hominis $(1 \% ; 1 / 142)$, S. hyicus $(1 \% ; 1 / 142)$ and S. scuiri $(1 \%$; $1 / 142)$.

Of the isolates tested, $18 \%(26 / 142)$ formed biofilm. Among biofilm producing isolates, $11 \%$ were S. chromogenes, followed by S. haemolyticus (4\%) and S. epidermidis (1\%). No biofilm formation was identified in S. scuiri and S. hyicus (Table 1).

In total, 90\% (128/142) of CoNS were resistant to at least one antimicrobial (AMR), with most isolates resistant to ampicillin (63\%) and penicillin (63\%). Few CoNS isolates were resistant to cloxacillin (16\%), cefoxitin (9\%), and vancomycin (9\%). More than half $(51 \%, 73 / 142)$ of CoNS were multidrug resistant (MDR). Multidrug resistant CoNS were mainly resistant to penicillin $(88 \%)$, ampicillin (85\%) and erythromycin (64\%) (Table 2). The most common resistant patterns identified among CoNS were penicillin-ampicillin $(16 \% ; 17 / 106)$ and penicillinampicillin-erythromycin $(10 \% ; 11 / 106)$.

Among biofilm positive CoNS, 92\% (24/26) were resistant to at least one antimicrobial, half of the isolates were resistant to erythromycin (54\%) and penicillin (50\%). While 42\% (11/26) of biofilm positive isolates were MDR. Biofilm positive isolates with MDR were resistant to penicillin (82\%), erythromycin (73\%), ampicillin (64\%) and streptomycin (55\%) (Table 3).

\section{Staphylococcus chromogenes species}

Ninety-three percent (93/100) of S. chromogenes were resistant to at least one antimicrobial. Isolates were mainly resistant to ampicillin (66\%), penicillin (63\%) and erythromycin (54\%). Low resistance was observed to vancomycin (11\%) and cefoxitin (6\%). Multidrug resistant $S$. chromogenes $(52 \% ; 52 / 100)$ exhibited a high prevalence of resistant to penicillin (87\%), ampicillin (87\%), erythromycin (69\%) and streptomycin (54\%) (Table 4). The most common resistant patterns among S. chromogenes were the penicillin-ampicillin-erythromycin (91\%)

Table 1 Biofilm formation of coagulase-negative Staphylococcus species $(n=142)$ isolated from cow milk samples at the Onderstepoort milk laboratory, 2017

\begin{tabular}{|c|c|c|c|c|c|c|c|c|}
\hline \multirow[t]{2}{*}{ Organism } & \multirow[t]{2}{*}{ Tested } & \multicolumn{3}{|c|}{ Number of Biofilm forming Isolates } & \multicolumn{4}{|c|}{ Total Biofilm formation } \\
\hline & & Weak & Moderate & Strong & Number & Percent & $95 \%$ & $\mathrm{Cl}^{\mathrm{a}}$ \\
\hline S. chromogenes & 100 & 6 & 7 & 3 & 16 & 11 & 7 & 18 \\
\hline S. epidermidis & 17 & 1 & 0 & 0 & 1 & 1 & 0 & 4 \\
\hline S. haemolyticus & 16 & 4 & 2 & 0 & 6 & 4 & 18 & 61 \\
\hline S. hominis & 1 & 0 & 0 & 1 & 1 & 1 & 1 & 7 \\
\hline S. scuiri & 1 & 0 & 0 & 0 & - & - & - & - \\
\hline S. xylosus & 3 & 1 & 0 & 0 & 1 & 1 & 0 & 4 \\
\hline S. simulans & 3 & 1 & 0 & 0 & 1 & 1 & 0 & 4 \\
\hline S. hyicus & 1 & 0 & 0 & 0 & - & - & - & - \\
\hline
\end{tabular}

${ }^{\mathrm{a}} 95 \% \mathrm{Cl}=95 \%$ confidence interval 
Table 2 Antimicrobial resistance patterns of coagulase-negative Staphylococcus species isolated from cow milk samples at the Onderstepoort milk laboratory, 2017

\begin{tabular}{|c|c|c|c|c|c|c|c|}
\hline \multirow[t]{2}{*}{ Group } & \multirow[t]{2}{*}{ Antimicrobial } & \multicolumn{3}{|c|}{ AMR-CoNS $^{\mathrm{b}}(n=142)$} & \multicolumn{3}{|c|}{ MDR-CoNS $(n=73)$} \\
\hline & & Percent & $95 \%$ & $\mathrm{Cl}^{\mathrm{a}}$ & Percent & $95 \%$ & $\mathrm{Cl}^{\mathrm{a}}$ \\
\hline Lincosamide & Clindamycin & 11 & 7 & 17 & 19 & 12 & 30 \\
\hline \multirow[t]{3}{*}{ Penicillins } & Penicillin & 63 & 55 & 70 & 88 & 78 & 93 \\
\hline & Ampicillin & 63 & 55 & 71 & 85 & 75 & 91 \\
\hline & Cloxacillin & 16 & 11 & 23 & 30 & 21 & 41 \\
\hline Tetracyclines & Oxytetracycline & 11 & 7 & 17 & 21 & 13 & 31 \\
\hline Phenicols & Chloramphenicol & 6 & 3 & 11 & 10 & 5 & 18 \\
\hline Flouroquinolone & Ciprofloxacin & 8 & 4 & 13 & 12 & 7 & 22 \\
\hline Cephalosporin & Cefoxitin & 9 & 5 & 15 & 18 & 11 & 28 \\
\hline Glycopeptide & Vancomycin & 9 & 5 & 15 & 16 & 10 & 27 \\
\hline Aminoglycoside & Streptomycin & 30 & 23 & 38 & 47 & 36 & 58 \\
\hline Macrolide & Erythromycin & 49 & 41 & 58 & 64 & 53 & 74 \\
\hline
\end{tabular}

${ }^{\mathrm{a}} 95 \% \mathrm{Cl}=95 \%$ confidence interval

${ }^{b}$ AMR-CoNS = Antimicrobial resistance of coagulase negative Staphylococcus species resistant to at least one antimicrobial

${ }^{\mathrm{C}} \mathrm{MDR}-\mathrm{CoNS}=$ Multidrug resistance coagulase negative Staphylococcus species

and penicillin-ampicillin pattern (71\%). Among biofilm positive $S$. chromogenes, 50\% (8/16) were MDR.

\section{Staphylococcus epidermidis species}

Overall, 94\% (16/17) of S. epidermidis were resistant to at least one antimicrobial while $65 \%(11 / 17)$ were MDR. The resistance was high to penicillin (82\%) and ampicillin (77\%). Few isolates were resistant to vancomycin (12\%), cloxacillin (35\%) and cefoxitin (29\%). Multidrug resistant S. epidermidis showed an increased prevalence of resistance to penicillin (91\%) and ampicillin (91\%) (Table 5). Twenty-five percent (1/4) of the biofilm positive $S$. epidermidis were resistant to at least one antimicrobial while none of the biofilm positive $S$. epidermidis isolates were MDR.

\section{Staphylococcus haemolyticus species}

Eighty-one percent (13/16) of S. haemolyticus were resistant to at least one antimicrobial, while $44 \%(7 / 16)$ were MDR. The highest prevalence of resistance observed was to penicillin (56\%) and few isolates were resistant to cloxacillin (13\%) and cefoxitin (13\%). Multidrug resistant $S$. haemolyticus were mainly resistant to penicillin (100\%), ampicillin (71\%), and erythromycin (57\%) (Table 6). Among S. haemolyticus biofilm positive isolates, 100\% (6/

Table 3 Antimicrobial resistance patterns of biofilm positive coagulase-negative Staphylococcus species isolated from cow milk samples at the Onderstepoort milk laboratory, 2017

\begin{tabular}{|c|c|c|c|c|c|c|c|}
\hline \multirow[t]{2}{*}{ Group } & \multirow[t]{2}{*}{ Antimicrobial } & \multicolumn{3}{|c|}{$\begin{array}{l}\text { AMR-CoNS b biofilm positive } \\
(n=24)\end{array}$} & \multicolumn{3}{|c|}{$\begin{array}{l}\text { MDR-CoNS }{ }^{c} \text { biofilm positive } \\
(n=11)\end{array}$} \\
\hline & & Percent & $95 \%$ & $\mathrm{Cl}^{\mathrm{a}}$ & Percent & $95 \%$ & $\mathrm{Cl}^{\mathrm{a}}$ \\
\hline Lincosamide & Clindamycin & 21 & 9 & 41 & 36 & 15 & 65 \\
\hline \multirow[t]{3}{*}{ Penicillins } & Penicillin & 54 & 35 & 72 & 82 & 52 & 95 \\
\hline & Ampicillin & 42 & 25 & 61 & 64 & 35 & 85 \\
\hline & Cloxacillin & 4 & 1 & 20 & 9 & 2 & 38 \\
\hline Tetracyclines & Oxytetracycline & 8 & 2 & 26 & 18 & 5 & 48 \\
\hline Phenicols & Chloramphenicol & 8 & 2 & 26 & 18 & 5 & 48 \\
\hline Flouroquinolone & Ciprofloxacin & 13 & 4 & 31 & 18 & 5 & 48 \\
\hline Cephalosporin & Cefoxitin & 8 & 2 & 26 & 18 & 5 & 48 \\
\hline Glycopeptide & Vancomycin & 8 & 2 & 26 & 9 & 2 & 38 \\
\hline Aminoglycoside & Streptomycin & 46 & 28 & 65 & 55 & 28 & 79 \\
\hline Macrolide & Erythromycin & 58 & 39 & 76 & 73 & 43 & 90 \\
\hline
\end{tabular}

${ }^{\mathrm{a}} 95 \% \mathrm{Cl}=95 \%$ confidence interval

${ }^{\mathrm{b}} \mathrm{AMR}-\mathrm{CoNS}=$ Antimicrobial resistance of coagulase negative Staphylococcus species resistant to at least one antimicrobial

${ }^{\mathrm{c}} \mathrm{MDR}-\mathrm{CoNS}=$ Multidrug resistance of coagulase negative Staphylococcus species 
Table 4 Antimicrobial resistance pattens of Staphylococcus chromogenes isolated from cow milk samples at the Onderstepoort milk laboratory, 2017

\begin{tabular}{|c|c|c|c|c|c|c|c|}
\hline \multirow[t]{2}{*}{ Group } & \multirow[t]{2}{*}{ Antimicrobial } & \multicolumn{3}{|c|}{$\begin{array}{l}\text { AMR-S. chromogenes } \\
(n=100)\end{array}$} & \multicolumn{3}{|c|}{$\begin{array}{l}\text { MDR-S. chromogenes }{ }^{c} \\
(n=52)\end{array}$} \\
\hline & & Percentage & $95 \%$ & $\mathrm{Cl}^{\mathrm{a}}$ & Percentage & $95 \%$ & $\mathrm{Cl}^{\mathrm{a}}$ \\
\hline Lincosamide & Clindamycin & 14 & 9 & 22 & 25 & 15 & 38 \\
\hline \multirow[t]{3}{*}{ Penicillins } & Penicillin & 63 & 53 & 72 & 87 & 75 & 93 \\
\hline & Ampicillin & 66 & 56 & 75 & 87 & 75 & 93 \\
\hline & Cloxacillin & 14 & 9 & 22 & 25 & 15 & 38 \\
\hline Tetracyclines & Oxytetracycline & 6 & 3 & 12 & 12 & 5 & 23 \\
\hline Phenicols & Chloramphenicol & 4 & 2 & 10 & 8 & 3 & 18 \\
\hline flouroquinolone & Ciprofloxacin & 4 & 2 & 10 & 6 & 2 & 16 \\
\hline Cephalosporin & Cefoxitin & 6 & 3 & 12 & 12 & 5 & 23 \\
\hline Glycopeptide & Vancomycin & 11 & 6 & 19 & 19 & 11 & 32 \\
\hline Aminoglycoside & Streptomycin & 34 & 25 & 44 & 54 & 41 & 67 \\
\hline Macrolide & Erythromycin & 54 & 44 & 63 & 69 & 56 & 80 \\
\hline
\end{tabular}

${ }^{\mathrm{a}} 95 \% \mathrm{Cl}=95 \%$ confidence interval

${ }^{\mathrm{b}} \mathrm{AMR}-\mathrm{S}$. chromogenes $=\mathrm{S}$. chromogenes resistant to at least one antimicrobial

${ }^{\mathrm{C}}$ MDR- S. chromogenes $=$ Multidrug resistance $S$. chromogenes

6) were resistant to at least one antimicrobial while $50 \%$ (3/6) of the isolates were MDR.

\section{Discussion}

Coagulase negative Staphylococcus species (CoNS) have been reported as a cause of mastitis in dairy cattle [13] with prognosis in affected patients dependent on antimicrobial resistance profile of the isolate, the presence of virulence factors, and biofilm formation [29]. In this study, we investigated antimicrobial resistance patterns and biofilm formation of CoNS isolated from cow milk samples submitted to the Onderstepoort milk laboratory.

\section{Biofilm formation of CoNS}

We observed a low (18\%) proportion of biofilm-forming CoNS compared to other studies [20, 31, 32] For example, Tremblay et al. [31] in Canada reported 96.7\% proportion of biofilm formation in CoNS from dairy cattle with mastitis. Similarly, $85.1 \%$ of CoNS from subclinical and clinical mastitis cases of dairy cattle in Argentina formed biofilm

Table 5 Antimicrobial resistance patterns of Staphylococcus epidermidis isolated from cow milk samples at the Onderstepoort milk laboratory, 2017

\begin{tabular}{|c|c|c|c|c|c|c|c|}
\hline \multirow[t]{2}{*}{ Group } & \multirow[t]{2}{*}{ Antimicrobial } & \multicolumn{3}{|c|}{$\begin{array}{l}\text { AMR-S. epidermidis } \\
(n=16)\end{array}$} & \multicolumn{3}{|c|}{$\begin{array}{l}\text { MDR-S. epidermidis }^{c} \\
(n=11)\end{array}$} \\
\hline & & Percent & $95 \%$ & $\mathrm{Cl}^{\mathrm{a}}$ & Percent & $95 \%$ & $\mathrm{Cl}^{\mathrm{a}}$ \\
\hline Lincosamide & Clindamycin & 0 & 0 & 18 & 0 & 0 & 26 \\
\hline \multirow[t]{3}{*}{ Penicillins } & Penicillin & 82 & 59 & 94 & 91 & 62 & 98 \\
\hline & Ampicillin & 77 & 53 & 90 & 91 & 62 & 98 \\
\hline & Cloxacillin & 35 & 17 & 59 & 55 & 28 & 79 \\
\hline Tetracyclines & Oxytetracycline & 41 & 22 & 64 & 64 & 35 & 85 \\
\hline Phenicols & Chloramphenicol & 17 & 6 & 41 & 18 & 5 & 48 \\
\hline flouroquinolone & Ciprofloxacin & 17 & 6 & 41 & 27 & 10 & 57 \\
\hline Cephalosporin & Cefoxitin & 29 & 13 & 53 & 45 & 21 & 72 \\
\hline Glycopeptide & Vancomycin & 12 & 3 & 34 & 18 & 5 & 48 \\
\hline Aminoglycoside & Streptomycin & 12 & 3 & 34 & 18 & 5 & 48 \\
\hline Macrolide & Erythromycin & 41 & 22 & 64 & 45 & 21 & 72 \\
\hline
\end{tabular}

${ }^{\mathrm{a}} 95 \% \mathrm{Cl}=95 \%$ confidence interval

${ }^{\mathrm{b}} \mathrm{AMR}-\mathrm{S}$. epidermidis $=\mathrm{S}$. epidermidis to at least one antimicrobial

${ }^{\mathrm{C}}$ MDR- $\mathrm{S}$. epidermidis = Multidrug resistance $S$. epidermidis 
Table 6 Antimicrobial resistance patterns of Staphylococcus haemolyticus, isolated from cow milk samples at the Onderstepoort milk laboratory, 2017

\begin{tabular}{|c|c|c|c|c|c|c|c|}
\hline \multirow[t]{2}{*}{ Group } & \multirow[t]{2}{*}{ Antimicrobial } & \multicolumn{3}{|c|}{$\begin{array}{l}\text { AMR-S. haemolyticus } \\
(n=13)\end{array}$} & \multicolumn{3}{|c|}{$\begin{array}{l}\text { MDR-S. haemolyticus }{ }^{c} \\
(n=7)\end{array}$} \\
\hline & & Percent & $95 \%$ & $\mathrm{Cl}^{\mathrm{a}}$ & Percent & $95 \%$ & $\mathrm{Cl}^{\mathrm{a}}$ \\
\hline Lincosamide & Clindamycin & 6 & 1 & 28 & 14 & 3 & 51 \\
\hline \multirow[t]{3}{*}{ Penicillins } & Penicillin & 56 & 33 & 77 & 100 & 65 & 100 \\
\hline & Ampicillin & 44 & 23 & 67 & 71 & 36 & 92 \\
\hline & Cloxacillin & 13 & 3 & 36 & 29 & 8 & 64 \\
\hline Tetracyclines & Oxytetracycline & 13 & 3 & 36 & 29 & 8 & 64 \\
\hline Phenicols & Chloramphenicol & 6 & 1 & 28 & 14 & 3 & 51 \\
\hline flouroquinolone & Ciprofloxacin & 19 & 7 & 43 & 29 & 8 & 64 \\
\hline Cephalosporin & Cefoxitin & 13 & 3 & 36 & 29 & 8 & 64 \\
\hline Glycopeptide & Vancomycin & 0 & 0 & 19 & 0 & 0 & 35 \\
\hline Aminoglycoside & Streptomycin & 31 & 14 & 56 & 43 & 16 & 75 \\
\hline Macrolide & Erythromycin & 25 & 10 & 50 & 57 & 25 & 84 \\
\hline
\end{tabular}

${ }^{\mathrm{a}} 95 \% \mathrm{Cl}=95 \%$ confidence interval

${ }^{\mathrm{b}} \mathrm{AMR}-\mathrm{S}$. haemolyticus $=\mathrm{S}$. haemolyticus resistant to at least one antimicrobial

${ }^{\mathrm{C}}$ MDR- S. haemolyticus $=$ Multidrug resistance of $S$. haemolyticus

[20]. Simojoki et al. [32] in Finland also reported a high (31.3\%) proportion of biofilm-forming CoNS from clinical mastitis cases in dairy cattle. The low proportion of biofilm formation of CoNS in this study compared to the above-mentioned studies may be attributed to the difference the growth media used [33], since, Tremblay et al. [31] and Simojoki et al. [32] used brain heart infusion for biofilm assay while in this study TSB was used. Nonetheless, the low proportion of biofilm formation in this study suggests that biofilm formation is not common in CoNS subclinical mastitis. Therefore, the role played by biofilm formation in the prognosis of CoNS subclinical mastitis in this study is limited. However, more studies need to be done to further explore the molecular epidemiology of biofilm formation CoNS from subclinical and clinical mastitis cases in dairy cattle, South Africa.

\section{Antimicrobial resistance of CoNS}

A high (90\%) proportion of CoNS in this study were resistant to at least one antimicrobial and no significant difference was observed in the proportion of resistance among CoNS species. Antimicrobial resistance in this study was higher than $21.4 \%$ reported in clinical mastitis cases of lactating cows in Sweden [34]. The reason for the high proportion of resistant CoNS isolates in this study is not clear. However, this could be due to selection pressure associated with injudicious use of antimicrobials for the treatment of clinical mastitis in dairy cattle from South Africa [21]. Moreover, antimicrobial drugs are easily available for farmers as over the counter medication [35]. Studies investigating antimicrobial use among farmers in the dairy industry in South Africa will be beneficial in understanding their role in antimicrobial stewardship. In addition, findings of this study suggest that interventions in the use of antimicrobial treatment among farmers in South Africa including restriction of antimicrobial use, limitation of over the counter antimicrobial, veterinary consultation, and the improvement of knowledge on antimicrobial resistance must be considered.

\section{Penicillin resistance}

A higher (63\%) proportion of penicillins resistant CoNS was observed in this study compared to that reported in clinical mastitis of dairy cattle in Finland (32\%) [32], Estonia (38.5\%) [36], and Zimbabwe (8\%) [5]. In contrast to other studies $[37,38]$, we observed no difference in the proportion of penicillin resistance among CoNS species. The high proportion of penicillin resistance in this study could be due to the low affinity associated with penicillin-binding protein 2a (PBP2a) produced by Staphylococcus species [16, 22, 23]. In addition, this could also be due to overuse of these antimicrobials as they are readily available as over the counter antimicrobials for treatment of mastitis in dairy cattle in South Africa [39] mainly due to their narrow-spectrum activity $[26,34,40]$.

\section{Erythromycin resistance}

The resistance to erythromycin among CoNS was higher (49\%) in this study than reported in subclinical mastitis of dairy cattle in Argentina (29\%) [17] and in Germany (22\%) [41]. In contrast, a higher (73.2\%) proportion of erythromycin resistant CoNS has been reported in a study done on subclinical mastitis cases of dairy cattle in Turkey [37]. The presence of erythromycin resistance in this study may be attributed to the presence of a 
ribosomal methylase based resistance, encoded by msrA and erm C [42]. Furthermore, Luthje et al. [41] suggest that alteration of the ribosomal methylase activity in Staphylococcus spp. could lead to horizontal gene transfer. Although erythromycin is one of the antimicrobial drugs used for control of CoNS isolates in bovine mastitis, it is not used for the treatment of CoNS in South Africa. Therefore, the high prevalence of resistance observed in this study needs further investigation.

\section{Vancomycin resistance}

Vancomycin resistance among CoNS in this study was uncommon $(9 \%)$ compared to the $58.2 \%$ reported in subclinical bovine mastitis cases in Turkey [37]. In contrast, Bengtsson et al. [34] in Sweden reported no vancomycin resistance among CoNS isolated from mastitis cases in dairy cattle. Although vancomycin is not currently used for the treatment of clinical mastitis in South Africa, other peptides antimicrobial drugs such as bacitracin are used in combination intramammary applications. The presence of vancomycin resistance CoNS is of public health significance as vancomycin is the drug of choice for treatment of MRSA in human medicine [2]. Therefore, measures must be implemented including restriction on the use of peptides antimicrobial drugs in the treatment of mastitis in the dairy industry to curb the potential development of vancomycin-resistant CoNS.

\section{Cefoxitin and $\beta$-lactam resistance}

The cefoxitin test is the preferred method for testing the CoNS for mecA mediated oxacillin resistance [43-45]. We observed a lower (9\%) proportion of cefoxitin resistant CoNS compared to the $29.41 \%$ reported in clinical mastitis cases from dairy cattle in Tunisia [46] and 40\% reported in subclinical mastitis from dairy cattle in Switzerland [47]. In addition, there was no significant difference in the proportion of cefoxitin resistant isolates within CoNS species. The presence of mecA mediated oxacillin resistance is suggestive of methicillin-resistant coagulase negative Staphylococcus species [1] and also encodes for penicillin-binding protein PBP2a. Together with the blaZ gene have been reported in $\beta$-lactam resistance among Staphylococcus species [9, 48]. Antimicrobial resistance of $\beta$-lactams is attributed to the hydrolysis and alteration of the $\beta$-lactam ring in bacteria [9] and is a common resistance mechanism to penicillins [31]. In this study, we observed a higher proportion of $\beta$-lactam resistant CoNS compared to the $23 \%$ reported in subclinical mastitis cases of dairy cows in Finland [13]. In contrast, all (100\%) CoNS isolates from clinical mastitis cases of dairy cattle in Argentina were $\beta$-lactam resistant [38]. The high presence of $\beta$-lactam resistant isolates and the potential presence of methicillin resistance among CoNS are likely to result in the poor clinical outcome as these isolates are likely to be resistant to other antimicrobial groups including tetracyclines, lincosamides, aminoglycosides, and macrolides [23, 43, 49, 50].

\section{Multidrug resistance and biofilm formation}

We observed a high (51\%) proportion of MDR-CoNS compared to $45 \%$ reported in clinical mastitis cases in India [27]. The high proportion of MDR-CoNS in this study could be attributed to the presence of mecA mediated oxacillin resistance and a high proportion of $\beta$ lactams resistant CoNS isolates [24-27]. Nonetheless, the high occurrence of MDR-CoNS further emphasizes the need for judicious use of antimicrobial drugs in the dairy industry in South Africa.

There was no significant difference in the presence of MDR among CoNS with biofilm formation compared to those without. To our knowledge, this is the first study to compare antimicrobial resistance patterns and biofilm formation in subclinical mastitis in dairy cattle. In contrast, a study done in clinical patients in human medicine reported a high prevalence of multidrug resistance in biofilm positive CoNS compared to biofilm negative CoNS [51]. In addition, multidrug resistance among $S$. aureus from human clinical isolates in Korea was more common in isolates with biofilm formation compared to those without [52]. In human medicine, Oliveira et al. [53] reported that bacteria grown as biofilm are up to 1000 times more resistant compared to planktonic. The results of this study suggest that there is no association between biofilm formation and multidrug resistance.

The study is not without limitation, the type of growth media used in the study to assay biofilm formation may have played a role in the low proportion of biofilm identified in this study as the chemical composition of growth media have been shown to influence the expression of biofilm-forming genes in bacteria [33]. In addition, vancomycin resistance was assessed using the disk diffusion method, however, the broth dilution antimicrobial test is the preferred method for analysis of vancomycin resistance [45]. The population of isolates used in this study came from samples submitted to one laboratory. Therefore, the results of this study should not be generalized to the entire dairy industry in South Africa.

\section{Conclusion}

Biofilm formation among the CoNS isolates in this study was uncommon and there was no significant different proportion of MDR-CoNS based on the ability to form a biofilm. The majority of CoNS in this study were resistance to penicillins. In addition, most isolates were $\beta$ lactams resistant and MDR.

The presence of high antimicrobial resistance in this study is a clinical concern and urgent actions should be taken to address the situation. Farmers in South Africa 
need to be made aware of the high MDR among CoNS and the need for judicious use of antimicrobials in the treatment of CoNS subclinical mastitis. The role of antimicrobial use practises in the development of resistance in subclinical mastitis in the dairy industry should be investigated. The relationship between antimicrobial resistance and biofilm formation in CoNS biofilm formation in the dairy industry is not clear and this concept needs further investigation.

\section{Methods}

\section{Data source}

Coagulase negative Staphylococci isolated from composite milk samples of subclinical mastitis cases that were submitted to the Onderstepoort milk laboratory, Faculty of Veterinary Science, University of Pretoria in 2017 were used. The laboratory receives milk samples from dairy farms across South Africa for routine diagnosis of mastitis. In total, 142 pure CoNS isolates were included in this study.

\section{Phenotypic identification}

Milk was plated out on bovine blood tryptose agar plates (Oxoid, Quantum Biotechnologies (Pty) Ltd., South Africa). Inoculated agar plates were incubated aerobically at $37^{\circ} \mathrm{C}\left( \pm 1^{\circ} \mathrm{C}\right)$ for $24-48 \mathrm{~h}$. Presumptive Staphylococcus spp. colonies were initially identified based on phenotypic morphology, and biochemical tests [54]. The Staphylococcus isolates were confirmed using Staph API (Biomerieux South Africa (Pty) Ltd., South Africa).

\section{Species identification using MALDI-TOFMS}

All Staphylococcus isolates were subjected to matrixassisted laser desorption ionisation time-of-flight mass spectrometry (MALDI-TOF-MS) as previously described $[55,56]$. Single pure colonies were transferred onto MALDI plates (Sigma Aldrich, St. Louis, MO) in duplicate and covered with $1 \mathrm{ll}$ of cyano-4-hydroxycinnamic acid in an organic solution (50\% acetonitrile and 2.5\% tri-fluoro-acetic acid). The preparation was crystallized by air drying at room temperature. Flex Control software (Bruker Daltonics) recorded spectra set for bacterial identification. MALDI Biolayer 3.0 software (Bruker Daltonics) with an integrated pattern-matching algorithm was used to compare generated peak lists against the reference library and a score was generated based on similarity.

\section{Biofilm formation}

The biofilm formation of CoNS isolates was investigated using the tissue culture plate method [57]. Isolates were cultured in BTA (blood tryptose agar) for $24 \mathrm{~h}$ at $37^{\circ} \mathrm{C}$. A loopful of a colony was then inoculated into $5 \mathrm{~mL}$ of trypticase soy broth (TSB) for $24 \mathrm{~h}$ at $37^{\circ} \mathrm{C}$. The inoculated broth was diluted using 1:100 to make a final volume of $2 \mathrm{ml}$ (1.98 ml TSB: $0.02 \mathrm{ml}$ inoculum). Individual wells of sterile 96 well flat bottom polystyrene tissue culture-treated plates (Sigma-Aldrich, Costar, USA) were filled with $200 \mu \mathrm{L}$ of the diluted broth, positive control and negative control in triplicate. The plates were incubated for $24 \mathrm{~h}$ at $37^{\circ} \mathrm{C}$. After incubation, the plates were read to obtain optical density (OD) before washing at a wavelength of $570 \mathrm{~nm}$ using a micro ELISA (enzymelinked immunosorbent assay) auto-reader (model 680, Biorad, UK). The contents of each well were then removed by gently tapping. The wells were washed with 200-300 ul of phosphate buffer saline (pH 7.4) three times while gently flicking the plates after each wash and left to dry for about $15 \mathrm{~min}$.

Biofilm formed and adhered to the wells were fixed using $150 \mathrm{ul}$ of (96\%) methanol for $20 \mathrm{~min}$, where after the contents were removed, and the plates were left to dry for $60 \mathrm{~min}$. Each well was stained with $150 \mathrm{ul}(0.2 \%)$ of crystal violet for $15 \mathrm{~min}, 150 \mathrm{ul}$ of (96\%) ethanol were then added into each well and covered for $30 \mathrm{~min}$ to elute the stain. The plates were read after washing at a wavelength of $570 \mathrm{~nm}$ using a micro ELISA auto-reader (model 680, Biorad, UK). This method was repeated 3 times and the OD (optical density) was averaged and subtracted from the cut off value to obtain the final OD for each isolate. A reference strain S. epidermidis ATCC 35984 was used as a control (Thermo Fischer).

The interpretation of the results was divided into the following categories; OD $\leq$ ODc (Optical density cut-off value) $=$ no biofilm producer; $\mathrm{ODc}<\mathrm{OD} \leq 2 \mathrm{XODc}=$ weak biofilm producer; $2 \mathrm{XODc}<\mathrm{OD} \leq 4 \mathrm{XODc}=$ moderate biofilm producer; $4 \mathrm{XODc}<\mathrm{OD}=$ strong biofilm producer [57]. For the purposes of analysis, weak, moderate, and strong biofilm were classified as biofilm positive.

\section{Antibiotic susceptibility testing}

Coagulase negative Staphylococcus isolates were subjected to antimicrobial susceptibility testing against a panel of 11 drugs using the disc diffusion method (Kirby-Bauer method) [45] on Mueller-Hinton agar according to Clinical and Laboratory Standards Institute guidelines. The antimicrobials investigated included 10 mcg ampicillin (AMP), 10 iu penicillin G (P), $30 \mu \mathrm{g}$ oxytetracycline (OT), $15 \mu$ g erythromycin (E), $30 \mu$ g chloramphenicol (C), $10 \mu \mathrm{g}$ streptomycin (S), $5 \mu \mathrm{g}$ ciprofloxacin (CIP), $30 \mu \mathrm{g}$ cefoxitin (FOX), $10 \mu \mathrm{g}$ vancomycin (VAN), $10 \mathrm{mcg}$ clindamycin (DA) and $5 \mathrm{mcg}$ cloxacillin (OB) [45]. Based on the diameter of the zone of inhibition, isolates were classified as sensitive, intermediate or resistant [45]. For the purpose of analysis, the intermediate susceptibility was considered as resistant. Isolates that were resistant to at least one antimicrobial drug were defined as "resistant" while those resistant to three or more antimicrobial categories were defined as "multidrug resistant" [58]. $\beta$ - 
lactams resistance was classified as resistant to at least penicillins, cephalosporins or carbapenems $[9,59]$. The interpretation of vancomycin was based on the criteria by Rezaeifar et al. [60].

\section{Data analysis}

The proportions and frequencies of all the variables together with their 95\% of confidence intervals were calculated and presented in table format.

\section{Abbreviations}

95\% Cl: 95\% confidence interval; AMP: Ampicillin; AMR: Resistance to one antimicrobial; BTA: Blood tryptose agar; C: Chloramphenicol; CIP: Ciprofloxacin; CoNS: Coagulase-negative Staphylococcus species; DA: Clindamycin; E: Erythromycin; EPS: Extracellular polysaccharide; FOX: Cefoxitin; IMI: Intramammary infection; MDR: Multidrug resistance; MHA: Mueller Hinton agar; MRSA: Methicillin resistant Staphylococcus aureus; OB: Cloxacillin; OD: Optical density; ODc: Optical cut-off density; OT: Oxytetracycline; PEN: Penicillins; QS: Quorum sensing; S: Streptomycin; TSB: Trypticase soy broth

\section{Acknowledgments}

The author would like to thank the Onderstepoort milk laboratory for providing the isolates for this study and staff members from the Section Veterinary Public Health (VPH) for all the assistance. Lastly, the authors thanks Dr. Joseph Erhabor for assisting with biofilm formation identification.

\section{Authors' contributions}

LP contributed to the design of the study, data analysis, interpretation, writing of the manuscript, and performed all the laboratory analysis. DN was the main supervisor and contributed to the design of the study, data analysis, the writing and final editing of the manuscript. IM assistance with study design, laboratory analysis and review of the final draft of the manuscript. All authors read and approved the final manuscript.

\section{Funding}

This research was funded by the Research Development Programme (RDP) of the University of Pretoria and the Milk Producers' Organisation (MPO).

\section{Availability of data and materials}

All the data used to support the findings of this study is available in the manuscript. Raw datasets may also be requested from the corresponding author provided that all ethical requirements have been met.

\section{Ethics approval}

The study was approved by the University of Pretoria Animal Ethics Committee (v046-18) as well as the Research Ethics Committee (REC024-18).

\section{Consent for publication}

Not applicable.

\section{Competing interests}

The authors declare that they have no competing interests.

\section{Author details}

${ }^{1}$ Section Veterinary Public Health, Department of Paraclinical Sciences, Faculty of Veterinary Science, University of Pretoria, Private Bag X04, Onderstepoort 0110, South Africa. ${ }^{2}$ Department of Production Animal Studies, Faculty of Veterinary Science, University of Pretoria, Private Bag X04, Onderstepoort 0110, South Africa.

Received: 12 August 2019 Accepted: 12 November 2019 Published online: 26 November 2019

\section{References}

1. Pitkälä A, Haveri M, Pyörälä S, Myllys V, Honkanen-Buzalski T. Bovine mastitis in Finland 2001_-prevalence, distribution of Bacteria, and antimicrobial resistance. J Dairy Sci. 2010;87:2433-41.
2. Foster T. Staphylococcus. In: Medical Microbiology. 4th ed. Galveston: University of Texas Medical Branch at Galveston; 1996. p. 1-11.

3. Schukken YH, González RN, Tikofsky LL, Schulte HF, Santisteban CG, Welcome FL, et al. CNS mastitis: nothing to worry about? Vet Microbiol. 2009;134:9-14.

4. Petzer I-MM, Karzis J, Watermeyer JC, van der Schans TJ, van Reenen R, van der Schans TJ, et al. Trends in udder health and emerging mastitogenic pathogens in South African dairy herds. J S Afr Vet Assoc. 2009;80:17-22.

5. Kudinha T, Simango C. Prevalence of coagulase-negative staphylococci in bovine mastitis in Zimbabwe. J S Afr Vet Assoc. 2012;73:62-5.

6. Fry PR, Middleton JR, Dufour S, Perry J, Scholl D, Dohoo I. Association of coagulasenegative staphylococcal species, mammary quarter milk somatic cell count, and persistence of intramammary infection in dairy cattle. J Dairy Sci. 2014;97:4876-85.

7. Taponen S, Koort J, Björkroth J, Saloniemi H, Pyörälä S. Bovine Intramammary infections caused by coagulase-negative staphylococci May persist throughout lactation according to amplified fragment length polymorphism-based analysis. J Dairy Sci. 2007;90:3301-7.

8. Sampimon OC, Barkema HW, Berends IMGA, Sol J, Lam TJGM. Prevalence and herd-level risk factors for intramammary infection with coagulasenegative staphylococci in Dutch dairy herds. Vet Microbiol. 2009;134:37-44.

9. Becker K, Heilmann C, Peters G. Coagulase-negative staphylococci. Clin Microbiol Rev. 2014;27:870-926.

10. El-Jakee JK, Aref NE, Gomaa A, El-Hariri MD, Galal HM, Omar SA, et al. Emerging of coagulase negative staphylococci as a cause of mastitis in dairy animals: An environmental hazard. Int J Vet Sci Med. 2013;1:74-8.

11. Xu J, Tan X, Zhang X, Xia X, Sun H. The diversities of staphylococcal species, virulence and antibiotic resistance genes in the subclinical mastitis milk from a single Chinese cow herd. Microb Pathog. 2015;88:29-38.

12. Bexiga R, Rato MG, Lemsaddek A, Semedo-Lemsaddek T, Carneiro C, Pereira $\mathrm{H}$, et al. Dynamics of bovine intramammary infections due to coagulasenegative staphylococci on four farms. J Dairy Res. 2014;81:208-14.

13. Taponen S, Simojoki H, Haveri M, Larsen HD, Pyörälä S. Clinical characteristics and persistence of bovine mastitis caused by different species of coagulase-negative staphylococci identified with API or AFLP. Vet Microbiol. 2006;115:199-207.

14. Pieterse R, Todorov SD. Bacteriocins - exploring alternatives to antibiotics in mastitis treatment. Braz J Microbiol. 2010;41:542-62.

15. Bhattacharyya D, Banerjee J, Bandyopadhyay S, Mondal B, Nanda PK, Samanta I, et al. First report on Vancomycin-resistant Staphylococcus aureus in bovine and Caprine Milk. Microb Drug Resist. 2016;22:675-81.

16. Koksal FÃ, Yasar H, Samasti M. Antibiotic resistance patterns of coagulasenegative staphylococcus strains isolated from blood cultures of septicemic patients in Turkey. Microbiol Res. 2009;164:404-10.

17. Raspanti CG, Bonetto CC, Vissio C, Pellegrino MS, Reinoso EB, Dieser SA, et al. Prevalencia y sensibilidad a antibióticos de especies de estafilococos coagulasanegativos provenientes de mastitis subclínica en bovinos de tambos de la regióncentral de Argentina. Rev Argent Microbiol. 2016:48:50-6.

18. Schmidt T, Kock MM, Ehlers MM. Diversity and antimicrobial susceptibility profiling of staphylococci isolated from bovine mastitis cases and close human contacts. J Dairy Sci. 2015;98:6256-69.

19. Beuron DC, Cortinhas CS, Botaro BG, Macedo SN, Gonçalves JL, Brito MAVP, et al. Risk factors associated with the antimicrobial resistance of Staphylococcus aureus isolated from bovine mastitis. Pesqui Vet Bras. 2014; 34:947-52.

20. Srednik ME, Tremblay YDN, Labrie J, Archambault M, Jacques M, Cirelli AF et al. Biofilm formation and antimicrobial resistance genes of coagulasenegative staphylococci isolated from cows with mastitis in Argentina. FEMS Microbiol Lett. 2017;364:fnx001.

21. Fair RJ, Tor Y. Antibiotics and bacterial resistance in the 21st century. Perspect Medicin Chem. 2014;6:25-64.

22. Brakstad OG, A. Maeland J. Mechanisms of methicillin resistance in staphylococci. Apmis. 2009;105:264-76.

23. Silva NCC, Guimarães FF, Manzi MDP, Gómez-Sanz E, Gómez P, Araújo JP, et al. Characterization of methicillin-resistant coagulase-negative staphylococci in milk from cows with mastitis in Brazil. Antonie van Leeuwenhoek Int J Gen Mol Microbiol. 2014;106:227-33.

24. Jain A, Agarwal J, Bansal S. Prevalence of methicillin-resistant, coagulasenegative staphylococci in neonatal intensive care units: findings from a tertiary care hospital in India. J Med Microbiol. 2004;53:941-4.

25. Wilkinson AR, Massey RC, Kantzanou M, de Silva GDI, Day NPJ, Justice A, et al. The Ica operon and biofilm production in coagulase-negative 
staphylococci associated with carriage and disease in a neonatal intensive care unit. J Clin Microbiol. 2002;40:382-8.

26. Szweda P, Schielmann M, Frankowska A, Kot B, Zalewska M. Antibiotic resistance in Staphylococcus aureus strains isolated from cows with mastitis in eastern Poland and analysis of susceptibility of resistant strains to alternative nonantibiotic agents: lysostaphin, nisin and polymyxin B. J Vet Med Sci. 2014;76:355-62.

27. Mahato S, Mistry HU, Chakraborty S, Sharma P, Saravanan R, Bhandari V. Identification of variable traits among the methicillin resistant and sensitive coagulase negative staphylococci in milk samples from mastitic cows in india. Front Microbiol. 2017:8:1446.

28. Yu W, Kim HK, Rauch S, Schneewind O, Missiakas D. Pathogenic conversion of coagulase-negative staphylococci. Microbes Infect. 2017;19:101-9.

29. Cepas V, López Y, Muñoz E, Rolo D, Ardanuy C, Martí S, et al. Relationship between biofilm formation and antimicrobial resistance in gram-negative Bacteria. Microb Drug Resist. 2019;25:72-9.

30. Tremblay YDN, Caron V, Blondeau A, Messier S, Jacques M. Biofilm formation by coagulase-negative staphylococci: impact on the efficacy of antimicrobials and disinfectants commonly used on dairy farms. Vet Microbiol. 2014;172:511-8.

31. Tremblay YDN, Lamarche $D$, Chever $P$, Haine D, Messier $S$, Jacques M. Characterization of the ability of coagulase-negative staphylococci isolated from the milk of Canadian farms to form biofilms. J Dairy Sci. 2012;96:234-46.

32. Simojoki H, Hyvönen P, Plumed Ferrer C, Taponen S, Pyörälä S. Is the biofilm formation and slime producing ability of coagulase-negative staphylococci associated with the persistence and severity of intramammary infection? Vet Microbiol. 2012;158:344-52.

33. Fabres-Klein MH, Caizer Santos MJ, Contelli Klein R, Nunes de Souza G, de Oliveira Barros Ribon A. An association between milk and slime increases biofilm production by bovine Staphylococcus aureus. BMC Vet Res. 2015;11:1-8.

34. Bengtsson B, Unnerstad HE, Ekman T, Artursson K, Nilsson-Öst M, Waller KP. Antimicrobial susceptibility of udder pathogens from cases of acute clinical mastitis in dairy cows. Vet Microbiol. 2009;136:142-9.

35. Oguttu JW, Qekwana DN, Odoi A. An exploratory descriptive study of antimicrobial resistance patterns of Staphylococcus Spp. Isolated from Horses Presented at a Veterinary Teaching Hospital. BMC Vet Res. 2017;13:269.

36. Pitkälä A, Salmikivi L, Bredbacka P, Myllyniemi AL, Koskinen MT. Comparison of tests for detection of $\beta$-lactamase-producing staphylococci. J Clin Microbiol. 2007;45:2031-3.

37. Kenar B, Kuyucuoğlu Y, Şeker E. Antibiotic susceptibility of coagulasenegative staphylococci isolated from bovine subclinical mastitis in Turkey. Pak Vet J. 2012;32:390-3.

38. Gentilini E, Denamiel G, Betancor A, Rebuelto M, Rodriguez Fermepin M, De Torres RA. Antimicrobial susceptibility of coagulase-negative staphylococci isolated from bovine mastitis in Argentina. J Dairy Sci. 2010;85:1913-7.

39. Henton MM, Eagar HA, Swan GE, van Vuuren M. Part VI. Antibiotic management and resistance in livestock production. South African Med J. 2011;101:583-6.

40. Persson Waller K, Aspán A, Nyman A, Persson Y, Grönlund AU. CNS species and antimicrobial resistance in clinical and subclinical bovine mastitis. Vet Microbiol. 2011;152:112-6.

41. Lüthje P, Schwarz S. Antimicrobial resistance of coagulase-negative staphylococci from bovine subclinical mastitis with particular reference to macrolide-lincosamide resistance phenotypes and genotypes. J Antimicrob Chemother. 2006;57:966-9.

42. Sawant AA, Gillespie BE, Oliver SP. Antimicrobial susceptibility of coagulasenegative Staphylococcus species isolated from bovine milk. Vet Microbiol. 2009;134:73-81.

43. Suja KRS, Sheela P, Jyothis S, Radhakrishnan EK. Virulence factors associated with Coagulase Negative Staphylococci isolated from human infections. 3 Biotech. 2017:7:1-10

44. Hussain Z, Stoakes L, Massey V, Diagre D, Fitzgerald V, El Sayed S, et al Correlation of oxacillin MIC with mecA gene carriage in coagulase- negative staphylococci. J Clin Microbiol. 2000;38:752-4.

45. Clinical Laboratory Standards Insitute. Laboratory standards institute antimicrobial susceptibility testing standards M02-A12, M07-A10, and M11A8. 2017.

46. Klibi A, Maaroufi A, Torres C, Jouini A. Detection and characterization of methicillin-resistant and susceptible coagulase-negative staphylococci in milk from cows with clinical mastitis in Tunisia. Int J Antimicrob Agents. 2018:52:930-5.
47. Sakwinska O, Morisset D, Madec JY, Waldvogel A, Moreillon P, Haenni M Link between genotype and antimicrobial resistance in bovine mastitisrelated Staphylococcus aureus strains, determined by comparing swiss and French isolates from the Rh??Ne valley. Appl Environ Microbiol. 2011;77: 3428-32.

48. Osman K, Alvarez-Ordóñez A, Ruiz L, Badr J, ElHofy F, Al-Maary KS, et al. Antimicrobial resistance and virulence characterization of Staphylococcus aureus and coagulase-negative staphylococci from imported beef meat. Ann Clin Microbiol Antimicrob. 2017:16:35.

49. Ibadin EE, Enabulele IO, Muinah F. Prevalence of mecA gene among staphylococci from clinical samples of a tertiary hospital in Benin city, Nigeria. Afr Health Sci. 2017;17:1000-10.

50. May L, Klein EY, Rothman RE, Laxminarayan $\mathrm{R}$. Trends in antibiotic resistance in coagulase-negative staphylococci in the United States, 1999 to 2012. Antimicrob Agents Chemother. 2014;58:1404-9.

51. Shrestha LB, Bhattarai NR, Khanal B. Antibiotic resistance and biofilm formation among coagulase-negative staphylococci isolated from clinical samples at a tertiary care hospital of eastern Nepal. Antimicrob Resist Infect Control. 2017:6:89.

52. Kwon AS, Park GC, Ryu SY, Lim DH, Lim DY, Choi CH, et al. Higher biofilm formation in multidrug-resistant clinical isolates of Staphylococcus aureus. Int J Antimicrob Agents. 2008:32:68-72.

53. de Oliveira A, Pereira VC, Pinheiro L, Riboli DFM, Martins KB, Cunha M. Antimicrobial resistance profile of planktonic and biofilm cells of Staphylococcus aureus and coagulase-negative staphylococci. Int J Mol Sci. 2016;17:1423.

54. Markey B, Leonard F, Archambault M, Cullinane A, Maguire D. Clinical veterinary microbiology e-book. United States: Mosby Ltd; 2013.

55. Nonnemann B, Lyhs U, Svennesen L, Kristensen KA, Klaas IC, Pedersen K. Bovine mastitis bacteria resolved by MALDI-TOF mass spectrometry. J Dairy Sci. 2019;102:2515-24.

56. Fox K, Fox A, Rose J, Walla M. Speciation of coagulase negative staphylococci, isolated from indoor air, using SDS page gel bands of expressed proteins followed by MALDI TOF MS and MALDI TOF-TOF MS-MS analysis of tryptic peptides. J Microbiol Methods. 2011;84:243-50.

57. Stepanović S, Vuković D, Hola V, Di Bonaventura G, Djukić S, Ćirković I, et al. Quantification of biofilm in microtiter plates: overview of testing conditions and practical recommendations for assessment of biofilm production by staphylococci. APMIS. 2007;115:891-9.

58. Magiorakos AP, Srinivasan A, Carey RB, Carmeli Y, Falagas ME, Giske CG, et al. Multidrug-resistant, extensively drug-resistant and pandrug-resistant bacteria: an international expert proposal for interim standard definitions for acquired resistance. Clin Microbiol Infect. 2012;18:268-81.

59. Oliver SP, Murinda SE. Antimicrobial resistance of mastitis pathogens. Vet Clin North Am Food Anim Pract. 2012;28:165-85

60. Rezaeifar M, Bagher Bagheri M, Moradi M, Rezaeifar M. Assessment of disk diffusion and E-test methods to determine antimicrobial activity of cefalotin and vancomycin on clinical isolates of Staphylococcus aureus. Int J Med Res Heal Sci. 2016;5:122-6.

\section{Publisher's Note}

Springer Nature remains neutral with regard to jurisdictional claims in published maps and institutional affiliations.

Ready to submit your research? Choose BMC and benefit from

- fast, convenient online submission

- thorough peer review by experienced researchers in your field

- rapid publication on acceptance

- support for research data, including large and complex data types

- gold Open Access which fosters wider collaboration and increased citations

- maximum visibility for your research: over $100 \mathrm{M}$ website views per year

At $\mathrm{BMC}$, research is always in progress.

Learn more biomedcentral.com/submissions 